\title{
Sonographic Assessment of the Normal and Abnormal Feline Mammary Glands and Axillary and Inguinal Lymph Nodes
}

\author{
Nayara S. Moraes $(\mathbb{D}$ and Naida C. Borges $(\mathbb{D}$ \\ Department of Veterinary Medicine, Veterinary School and Animal Science (Escola de Veterinária e Zootecnica-EVZ), \\ Federal University of Goiás (Universidade Federal de Goiás-UFG), Highway Goiânia-Nova Veneza, km 8, Campus Samambaia, \\ Goiânia 74690-900, Goiás, Brazil \\ Correspondence should be addressed to Nayara S. Moraes; nayara_kika@discente.ufg.br
}

Received 7 March 2021; Revised 9 June 2021; Accepted 27 June 2021; Published 2 July 2021

Academic Editor: Remo Lobetti

Copyright (c) 2021 Nayara S. Moraes and Naida C. Borges. This is an open access article distributed under the Creative Commons Attribution License, which permits unrestricted use, distribution, and reproduction in any medium, provided the original work is properly cited.

\begin{abstract}
Ultrasound has been used as a diagnostic tool in normal mammary glands and mammary tumors of several species. This study aims to describe the B-mode and Doppler ultrasound features of the mammary glands and draining lymph nodes in 32 adult female cats. Group 1 (G1) consisted of 22 cats without changes in the mammary glands. The average age was $45 \pm 25.09$ months, where $63.6 \%(n=14)$ were neutered and $31.8 \%(n=7)$ had received progestin at some point for reproductive control. Mammary gland structure was predominantly hypoechoic and homogeneous, with well-defined margins. The average thickness was $1.52 \pm 1.59 \mathrm{~mm}$, although it may be affected by estrus, pregnancy, and lactation. In G1, 100\% of lymph nodes were homogeneous, $98 \%$ were hypoechoic, and $100 \%$ were with well-defined margins and hilar vascularization. Group 2 (G2) consisted of 10 cats with mammary nodules. The average age was $88.8 \pm 40.5$ months, and $70 \%$ were intact and all had already received progestin. Ultrasound demonstrated enlarged mammary glands, with nodules of different textures clinically, mainly affecting the abdominal mammary glands (61\%). In 33.33\%, there were visible mammary ducts. Only $54.17 \%$ were homogeneous, $95.83 \%$ were hypoechoic, and the margins were regular in $52.08 \%$. Lymph nodes in abnormal mammary chains may present changes in size, shape, echotexture, and echogenicity. Ultrasound examination of the mammary glands and lymph nodes are possible to evaluate the entire mammary chain as well the superficial inguinal and axillary lymph nodes for abnormalities in the feline.
\end{abstract}

\section{Introduction}

In veterinary medicine, neoplasia has been identified as one of the main causes of pet mortality and occurring predominantly in old age [1-3]. Felines are mainly affected by cutaneous neoplasms, lymphomas, and mammary neoplasms. Mammary neoplasia is the third most frequent cancer in these animals, representing $17 \%$ of the total of neoplasms in female cats and $12 \%$ of the total cats, when considering both genders [4-8].

The mammary gland most frequently affected by neoplasia in cats has not been determined, and studies are quite divergent [9-11]. Clinically, mammary tumors are firm, nodular, single, or multiple masses [12]. Ultrasound examination of the mammary gland provides information about the normal glandular parenchyma, but this pattern may present echogenicity variations due to hormonal action, such as during pregnancy and lactation $[10,11]$.

Ultrasound is a standard procedure for breast imaging in women due to rapid technological advancement, and it is indicated for the differentiation of solid and cystic nodules detected by mammography or evaluation of palpable nodules. This is usually the initial examination chosen in these patients due to the absence of ionizing radiation and high breast density in younger women [13-15].

There are few studies of the ultrasound evaluation of feline mammary glands, and this examination is not routinely performed in small animals. Ultrasound of superficial structures such as the mammary ducts and lymph nodes is difficult even when using high-frequency transducers. 
This study aims to describe the B-mode and Doppler ultrasound features of the normal mammary glands and regional lymph nodes (superficial axillary and inguinal) and to compare the normal ultrasound characteristics to those in abnormal mammary glands and lymph nodes.

\section{Materials and Methods}

The study was approved by the Animal Use Ethics Committee of Federal University of Goiás (CEUA/UFG) (number 076/17).

Clinical and historical data were collected from $36 \mathrm{fe}-$ male cats including breed, age, body weight, age at the first estrous cycle, administration of progestagins, previous or current pregnancy, clinical examination of the mammary glands by palpation, and visual analysis of the mammary chain. The inclusion criteria were bodyweight over $2 \mathrm{~kg}$, age of at least ten months old, and the cats needed to allow manual restraint during the ultrasound examination. Four cats did not meet these criteria and were excluded. The cats included were evaluated about the estrous cycle phase with empiric criteria, considering the history information about time of the last estrus.

Group 1 (G1) consisted of 22 cats without changes in the mammary chain and group 2 (G2) with 10 adult cats with palpable mammary alterations. In addition to breast chain ultrasound, all cats underwent abdominal and regional lymph node ultrasound. Additional thoracic radiography was performed on G2 cats to investigate possible metastatic lesions.

B-mode and Doppler mode ultrasound of the mammary chains and inguinal and axillary lymph nodes was performed with a SonoScape S6 Portable Ultrasound device (SonoScape Medical Corporation) with a $15 \mathrm{MHz}$ linear frequency for mammary gland evaluation and $7.5 \mathrm{MHz}$ linear frequency transducer for evaluation of the abdomen. Images were obtained in longitudinal and transverse planes and assessed for thickness, echotexture (homogeneous and heterogeneous), echogenicity (hyperechoic, isoechoic, and anechoic), margination (well defined, poorly defined, smooth, and irregular), the presence or absence of ducts, and the presence or absence of vascularization. The mammary gland data were divided into left and right cranial and caudal thoracic and cranial and caudal abdominal glands and assessed individually. Lymph nodes were similarly evaluated for shape (oval, rounded, or elongated), size (length and width), margins, echotexture, echogenicity, and vascularization and were classified as suspicious or not for regional metastatic lesions when relevant.

Axillary lymph nodes can be identified by scanning cranial-lateral cranial thoracic mammary glands (CrTMGs) with the transducer positioned parallel to the long axis of the body (longitudinal plane) with a slight medial inclination of the transducer at approximately $10^{\circ}$. The superficial inguinal lymph nodes of the cats are identifiable in a caudolateral scan to the caudal abdominal mammary glands (CaAMGs) with the transducer positioned in a longitudinal plane with a medial inclination of approximately $10^{\circ}$ to $15^{\circ}$. The caudal epigastric artery can be scanned a little deeper and cranially to superficial inguinal lymph nodes. The mammary chains scanning protocol was performed first in the longitudinal planes and later in the transverse planes, starting from the left superficial inguinal lymph node, following to the left caudal epigastric artery, the left (CaAMG), maintaining the cranial direction and the decreasing order of the mammary glands (CaAMG, CrAMG, CaTMG, and CrTMG) to the adjacent axillary lymph node and subsequently performing the same procedure on the right side.

The ultrasound findings of each animal were correlated to age, number of pregnancies, phase of the estrous cycle, reproductive status (intact or neutered), and whether or not the cat had received progestogens.

Radiographs were performed in left lateral, right lateral, and ventrodorsal projections (Philips ${ }^{\circledR}$, model KL74/20.40São Paulo, São Paulo, Brazil), and images were scanned by using the FCR CAPSULA (Fujifilm ${ }^{\circledR}$, model CR IR 357-São Paulo, São Paulo, Brazil).

Statistical analysis was performed by frequency calculations and comparison of means by Student's $t$-test, using Excel software from the Microsoft Office Professional Plus 2016 package.

\section{Results}

Group G1 $(n=22)$ ranged from 10 months to 108 months old (45 \pm 25.09 months), and 63.64\% $(n=14)$ were neutered, with the average age of ovariohysterectomy $11.76 \pm 7.44$ months. Among the eight intact cats (36.36\%), two were in anestrus, one in estrus, and five in diestrus. Seven $(31.82 \%)$ of the 22 cats had received progestogens, four of them were intact, and three were neutered at the moment of evaluation. Regardless of progestin use, at least one pregnancy was reported in $22.73 \%(n=5)$ of the cats at some point historically, but only one was pregnant at the time of scanning. Twenty cats presented with four pairs of mammary glands, one cat presented with five pairs, and one cat presented with a unilateral supernumerary mammary gland. Table 1 depicts the measured thickness of each mammary gland. Mammary ducts were only detected in three cats during late pregnancy, estrus, and lactation, respectively (cats $n^{\circ} 16,17$, and 18).

Mammary glands were classified as homogeneous (95\%) and heterogeneous (5\%) and as hypoechoic (75\%) and isoechoic (25\%) (Figure 1). The mammary tissues considered isoechoic were difficult to define as they had subtle margins poorly differentiated from adjacent tissues.

Mammary vascularization was observed with colour flow doppler only during lactation, being characterized by doppler flow, interspersed with the mammary ducts, and an increase in the caliber of a caudal superficial epigastric artery in the region adjacent to the inguinal lymph node.

Group $2(n=10)$ was cats with mammary nodules, with ages from 24 months to 144 months (average $88.8 \pm 40.5$ months). Of the cats, $70 \%(n=7)$ were intact, and all $(n=10)$ had received progestogen treatment, with $60 \%$ of them receiving regular treatment until the mammary nodules appeared. Previous pregnancy was reported in 50\% of the total $(n=5)$ cats. Nine cats had four pairs of mammary glands, and one cat had five pairs of mammary glands. 
TABLE 1: Individual values, average $(X)$, and standard deviations (SDs) related to age and mammary thickness assessed by ultrasonography in cats with normal mammary glands (G1).

\begin{tabular}{|c|c|c|c|c|c|c|c|c|c|}
\hline \multirow{4}{*}{ Cats } & \multirow{4}{*}{$\begin{array}{c}\text { Age } \\
\text { (months) }\end{array}$} & \multicolumn{8}{|c|}{ Mammary thickness $(\mathrm{mm})$} \\
\hline & & \multicolumn{4}{|c|}{$\begin{array}{c}\text { Thoracic mammary } \\
\text { gland }\end{array}$} & \multicolumn{4}{|c|}{$\begin{array}{l}\text { Abdominal mammary } \\
\text { gland }\end{array}$} \\
\hline & & \multicolumn{2}{|c|}{ Cranial } & \multicolumn{2}{|c|}{ Caudal } & \multicolumn{2}{|c|}{ Cranial } & \multicolumn{2}{|c|}{ Caudal } \\
\hline & & Right & Left & Right & Left & Right & Left & Right & Left \\
\hline 1 & 24 & 0.9 & 1.1 & 0.7 & 1.2 & 1.0 & 1.0 & 1.3 & 1.3 \\
\hline 2 & 48 & 0.9 & 1.3 & 0.7 & 0.7 & 1.2 & 1.4 & 1.5 & 1.1 \\
\hline 3 & 60 & 1.8 & 1.8 & 0.9 & 1.3 & 1.1 & 1.1 & 0.8 & 0.9 \\
\hline 4 & 48 & 0.5 & 1.2 & 0.9 & 1.0 & 1.1 & 0.9 & 1.9 & 1.3 \\
\hline 5 & 36 & 1.4 & 1.3 & 0.9 & 1.1 & 0.8 & 1.3 & 1.0 & 1.8 \\
\hline 6 & 66 & 0.7 & 0.8 & 1.7 & 1.1 & 0.6 & 1.5 & 0.7 & 0.4 \\
\hline 7 & 96 & 0.9 & 0.9 & 0.5 & 0.6 & 0.4 & 0.9 & 0.8 & 0.3 \\
\hline 8 & 24 & 1.2 & 0.6 & 0.8 & 0.7 & 1.1 & 1.1 & 0.9 & 1.2 \\
\hline 9 & 108 & 1.1 & 0.9 & 0.7 & 1.1 & 0.8 & 0.9 & 1.5 & 0.7 \\
\hline 10 & 48 & 1.3 & 1.6 & 1.5 & 0.7 & 0.9 & 0.9 & 1.2 & 1.2 \\
\hline 11 & 36 & 0.7 & 0.4 & 1.1 & 1.6 & 1.0 & 0.6 & 1.1 & 1.3 \\
\hline 12 & 60 & 0.4 & 0.6 & 1.0 & 0.6 & 0.8 & 0.6 & 1.3 & 0.9 \\
\hline 13 & 54 & 0.6 & 0.5 & 0.6 & 0.5 & 0.5 & 0.7 & 0.8 & 0.8 \\
\hline 14 & 60 & 1.5 & 1.5 & 1.4 & 2.0 & 0.9 & 1.0 & 0.5 & 0.8 \\
\hline 15 & 48 & 1.3 & 0.9 & 1.0 & 1.2 & 1.2 & 1.7 & 1.1 & 0.7 \\
\hline 16 & 24 & 1.1 & 1.1 & 1.6 & 1.3 & 2.6 & 3.5 & 6.1 & 3.9 \\
\hline 17 & 12 & 1.5 & 1.6 & 2.3 & 2.2 & 3.4 & 2.3 & 4.7 & 4.2 \\
\hline 18 & 24 & 7.2 & 6.2 & 3.9 & 6.0 & 9.0 & 6.2 & 10.3 & 11.1 \\
\hline 19 & 10 & 0.5 & 0.8 & 0.6 & 0.5 & 0.4 & 0.8 & 1.5 & 1.0 \\
\hline 20 & 48 & 0.9 & 1.0 & 1.3 & 1.7 & 1.3 & 1.3 & 2.0 & 1.9 \\
\hline 21 & 12 & 0.7 & 1.3 & 1.1 & 1.3 & 1.9 & 1.1 & 1.9 & 1.3 \\
\hline 22 & 36 & 0.9 & 1.1 & 0.9 & 0.9 & 1.0 & 1.0 & 1.2 & 1.0 \\
\hline$X$ & 45 & 1.3 & 1.3 & 1.2 & 1.3 & 1.5 & 1.4 & 2.0 & 1.8 \\
\hline SD & 25 & 1.3 & 11.1 & 0.7 & 1.1 & 1.8 & 1.2 & 2.2 & 2.3 \\
\hline
\end{tabular}

Table 2 documents the abnormal tissues (thickness). Of all G2 analyzed mammary glands, 31.25\% had mammary ducts present.

Palpation demonstrated nodules of different textures, ranging from very soft to very firm and adhering to adjacent tissues. $80 \%$ of cats had lesions on more than one mammary gland at the time of diagnosis. 14\% of all lesions found were in the cranial thoracic glands (right $=7 \%$ and left $=7 \%$ ), and in $24 \%$, the lesions occurred in the caudal thoracic glands (right $=10 \%$ and left $=14 \%$ ). The involvement of cranial abdominal mammary glands was present in 24\% (right$=17 \%$ and left $=7 \%$ ), while the affected caudal abdominal glands were present in $31 \%$ (right $=14 \%$ and left $=17 \%$ ). One patient in this group (patient $n^{\circ} 8$ ) had a pair of extra mammary gland at inguinal location, also affected by tumor lesions measuring up to $41.8 \mathrm{~mm}$ on both sides, making up $6 \%$ of the total (right $=3 \%$ and left $=3 \%$ ). Therefore, according to the study conducted, there is a higher probability of tumor involvement in abdominal breasts, which corresponded to $61 \%$ of all findings, compared to $38 \%$ of findings in thoracic mammary glands.

The mammary ducts were observed in $33.33 \%$ by B-mode examination, when considering both groups. Abnormal glands were homogeneous $(54.17 \%)$ and heterogeneous (45.83\%) echotextures, hypoechoic (95.83\%), had anechoic $(4.17 \%)$ appearance and regular margins, well delimited (52.08\%) and irregular, and difficult to delimit
(47.92\%) (Figure 2). Other signs observed were acoustic enhancement (55.56\%), posterior acoustic shadow (11.12\%), intratumoral sedimentation (38.90\%), and intratumoral vacuoles (anechogenic areas between intratumoral tissue) (33.34\%). Doppler mode vascularization identified tortuous vessels (70\%), peripheral vascularization (20\%), hilar-associated peripheral vascularization $(30 \%)$, intratumor-associated peripheral vascularization (20\%), and hilar and intratumoral-associated peripheral vascularization (20\%). Only $10 \%$ of mammary lesions did not present ultrasound alterations of the vasculature.

For the G1 lymph nodes (axillary and inguinal), 100\% were homogeneous, with well-defined margins and hilar vascularization, with the oval-shaped inguinal and the elongated axillary node, ranging from ovoid to flattened. $65 \%$ of lymph nodes had hypoechoic parenchyma with central hyperechogenic marking; in 33\%, the parenchyma was hypoechoic without a central echogenic marking, and in $2 \%$, the tissue was isoechoic with central hyperechogenic marking. 57.14\% lymph nodes of G2 were classified as oval shaped, $28.57 \%$ rounded, and $14.29 \%$ were oval shaped, but with easily identifiable lobes. Only 7.50\% of G2 lymph nodes had a well-defined central hyperechogenic marking (Figure 3).

Only two cats of G1 had accessory lymph nodes present, meaning that more than one lymph node was draining the mammary chain on either side. One cat had two lymph nodes in the right inguinal region and two lymph nodes in the left inguinal region, and another cat had two lymph nodes in the left axillary drainage. Cats of G2 showed no additional nodes.

The results of the abdominal ultrasound demonstrated changes in $60 \%$ of G 2 cats and $45.5 \%$ of G1 cats. Urinary sediment was the most common ultrasound finding, followed by splenomegaly, hepatomegaly, biliary sludge, renal cysts, uterine dilation, and hydronephrosis. When considering both groups, in $50 \%$ of cats, no changes were observed. Heterogeneous nodular masses, possibly secondary to mammary disease, were observed in one animal of G2 in the medial iliac lymph node associated with hepatomegaly and splenomegaly. Radiographic examination of the thorax showed possible pulmonary metastasis in $10 \%$ of G2 cats.

In $\mathrm{G} 2$, the cats $(30 \%)$ were neutered after 24 months of age, a period longer than that for the cats of $\mathrm{G} 1$, which were neutered at 11.7 months on average. Table 3 demonstrates the frequency between groups on different analyzed variables as some reproductive aspects, echogenicity, and echotexture of the mammary glands, as the presence of mammary ducts visible by ultrasound examination and lymph nodes sonogram characterization on each group.

\section{Discussion}

Specific knowledge is necessary in order to perform a mammary ultrasound in cats. Early neutered cats have underdeveloped mammary glands that make the examination more difficult to perform. We found that standard ultrasound examination of mammary glands is usually less than $2 \mathrm{~mm}$ thick and may increase during estrus, pregnancy, 


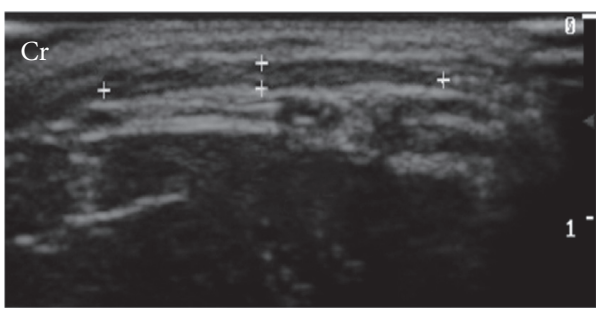

(a)

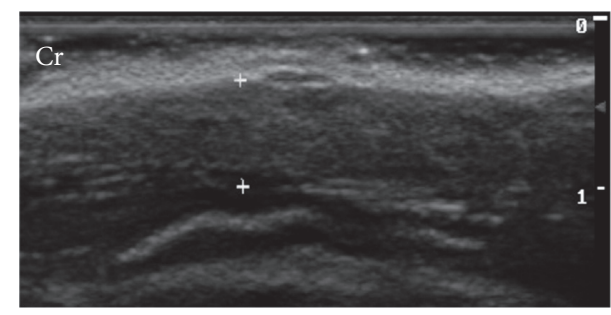

(b)

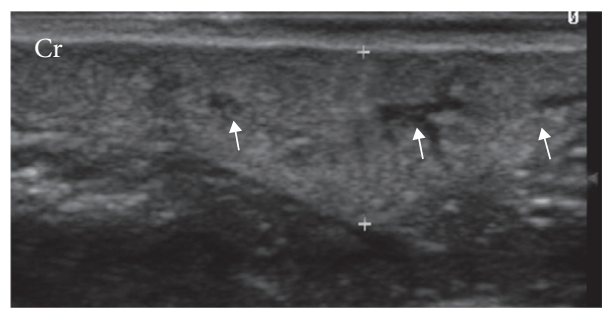

(c)

FIGURE 1: B-mode mammary gland ultrasound (between markers) of healthy cats during anestrus, at late pregnancy, and during lactation. (a) Right caudal thoracic mammary gland with homogeneous echotexture, hypoechoic parenchyma, and well-defined margins. (b) Right caudal abdominal mammary gland with homogeneous echotexture, hypoechoic parenchyma, and less distinct margins. (c) Left caudal abdominal mammary gland with heterogeneous echotexture, slightly hypoechoic parenchyma (comparing to superficial tissue), and the presence of anechogenic mammary ducts (arrows). Cr: cranial. Frequency $=15 \mathrm{MHz}$.

TABLE 2: Individual values, average $(X)$, and standard deviation (SD) related to age and mammary thickness assessed by ultrasonography in cats with mammary abnormalities (G2) based on palpable pathology.

\begin{tabular}{|c|c|c|c|c|c|c|c|c|c|}
\hline \multirow{4}{*}{ Cats } & \multirow{4}{*}{ Age (months) } & \multicolumn{8}{|c|}{ Mammary thickness (mm) } \\
\hline & & \multicolumn{4}{|c|}{ Thoracic mammary gland } & \multicolumn{4}{|c|}{ Abdominal mammary gland } \\
\hline & & \multicolumn{2}{|c|}{ Cranial } & \multicolumn{2}{|c|}{ Caudal } & \multicolumn{2}{|c|}{ Cranial } & \multicolumn{2}{|c|}{ Caudal } \\
\hline & & Right & Left & Right & Left & Right & Left & Right & Left \\
\hline 1 & 84 & 45.4 & 1.3 & 0.9 & 4.9 & 8.4 & 1.9 & 3.2 & 14.9 \\
\hline 2 & 60 & 1.3 & 1.2 & 1.5 & 1.7 & 2.2 & 1.9 & 2.7 & 2.3 \\
\hline 3 & 144 & 1.5 & 2.2 & 1.1 & 0.9 & 2.3 & 1.0 & 1.2 & 3.4 \\
\hline 4 & 132 & 7.0 & 3.0 & 8.0 & 6.0 & 13.0 & 39.0 & 51.0 & 28.0 \\
\hline 5 & 60 & 1.9 & 2.1 & 2.8 & 15.0 & 12.0 & 4.0 & 9.0 & 17.0 \\
\hline 6 & 48 & 0.9 & 1.1 & 31.0 & 2.2 & 4.2 & 5.0 & 3.5 & 3.9 \\
\hline 7 & 24 & 1.4 & 1.2 & 3.0 & 9.0 & 3.5 & 100.0 & 4.5 & 6.0 \\
\hline 8 & 108 & 1.8 & 1.5 & 1.9 & 2.3 & 2.1 & 2.2 & 2.8 & 12.6 \\
\hline 9 & 96 & 4.8 & 4.0 & 2.8 & 3.1 & 3.4 & 3.2 & 12.6 & 3.7 \\
\hline 10 & 132 & 2.2 & 1.5 & 7.2 & 2.8 & 2.1 & 2.3 & 2.5 & 2.7 \\
\hline$X$ & 88.8 & 6.8 & 1.9 & 6.0 & 4.8 & 5.3 & 16.0 & 9.3 & 9.5 \\
\hline SD & 40.5 & 13.7 & 0.9 & 9.1 & 4.3 & 4.2 & 31.6 & 15.1 & 8.5 \\
\hline
\end{tabular}

${ }^{*}$ Highlighted values are those with palpable nodules.

and lactation. This information was similar in the literature [11]. Mammary glands presented a hypoechogenic pattern and homogeneous echotexture during the anestrus and may present mammary ducts during estrus and diestrus during gestation or lactation. According to Payan-Carreira and Martins-Bessa [11], these ducts are responsible for the heterogeneity when the glands undergo hormonal actions, which was confirmed by our findings.

Extra- and supernumerary mammary glands were observed in three cats, and these findings were also described in female dogs $[8,16]$. In dogs, there are most commonly five pairs of glands, but supernumerary paired or unpaired glands may occur. Cats usually have four pairs [16].
In the G2, mammary pathology was detected at an average of 7.4 years of age, characterizing earlier involvement than in most published studies, which mention an average of 10 to 14 years of age $[3,12,17,18]$. In our study, $80 \%$ of the cats had nodular involvement in multiple mammary glands, similar to the reviewed literature $[1,9,19-21]$.

There was a higher probability of nodular involvement in abdominal mammary glands, corresponding to $62 \%$ of all findings, similar to a consulted study that found $62.96 \%$ [12]. However, the descriptions of the likelihood of nodular involvement in each gland are controversial $[12,19,20]$ requiring further studies. 


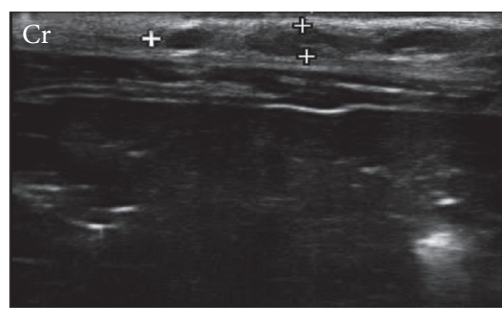

(a)

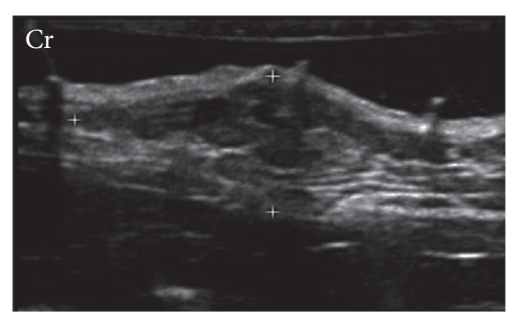

(b)

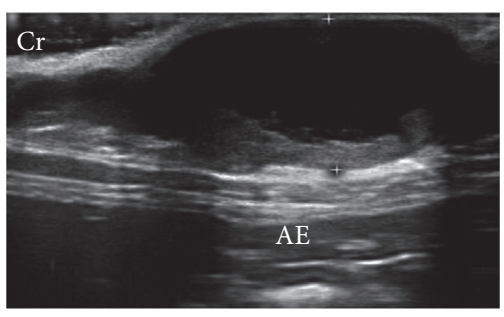

(c)

FiguRE 2: B-mode mammary ultrasound (between markers) of cats with mammary tumors during anestrus. (a) Left caudal abdominal mammary gland with hypoechoic parenchyma, poorly defined margins, and uneven edges. (b) Right cranial abdominal mammary gland with heterogeneous echotexture, uneven shape, unclear edges, and the presence of several lobulations. (c) Left caudal abdominal mammary gland with anechoic content and hypoechoic intratumoral sediment and well-defined margins, creating acoustic enhancement (AE). Cr: cranial. Frequency $=15 \mathrm{MHz}$.

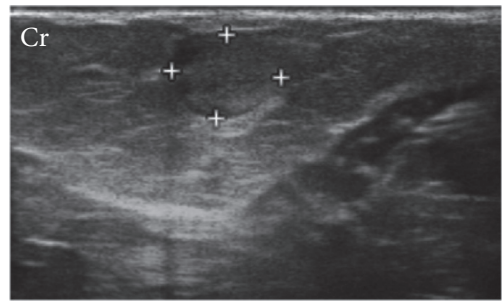

(a)

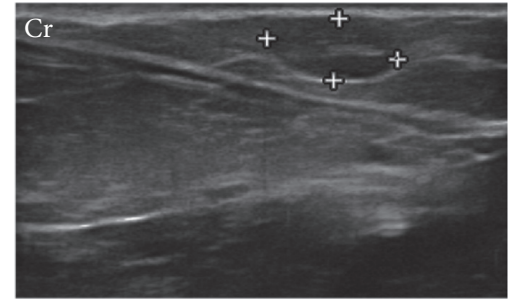

(b)

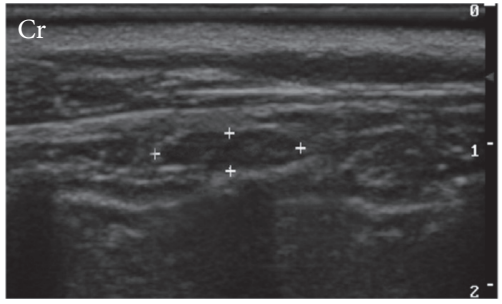

(c)

FIGURE 3: B-mode ultrasound of lymph nodes in a two-year-old cat with abnormal mammary glands and a three-year-old cat with normal mammary glands. (a) Right superficial inguinal lymph node (between the markers) of rounded shape and heterogeneous echotexture, without the central hyperechogenic line. (b) Left superficial inguinal lymph node (between markers) with oval shape, hypoechoic parenchyma, and homogeneous echotexture, with the central hyperechogenic line. (c) Right axillary lymph node (between markers) with elongated oval aspect, homogeneous echotexture, and hypoechoic parenchyma, without central hyperechogenic line. Cr: cranial. Frequency $=15 \mathrm{MHz}$.

All cats in the G2 group received progestogens, while only $31.82 \%$ of the healthy cats received the contraceptive. Several reversible contraceptive methods have been used in felines, but most protocols used have low efficacy and, especially, low safety [22]. The use of progestogens is related to the appearance of benign and malignant mammary neoplastic lesions $[8,12,22,23]$, due to simultaneous exposure of the mammary tissue to endogenous estrogen and progesterone with exogenous progestins, increasing progestin-induced diseases, then being contraindicated for cats since the risk of disease should be avoided [22]. Although, female cats have a reduced expression of estrogen receptors in neoplastic mammary tissue, with loss of hormonal dependence during malignant progression, explaining, in part, the high biological aggressiveness of malignant mammary tumors [19].

Only $30 \%$ of the G2 cats underwent ovariohysterectomy $(\mathrm{OHE})$. In these cats, there was no remaining ovary visible on the ultrasound examination, and the cats were neutered after two years of age which is more compared to the G1 group. OHE in cats when performed before one year is capable of reducing the risk of developing mammary gland cancer by up to $86 \%$ compared to nonovariohysterectomized cats $[8,17,23,24]$.

Two of the cats evaluated in G2 had distant nodules at the time of the study, and both had multiple mammary glands affected. One patient with a primary thoracic mammary nodule had a miliary interstitial lung pattern identified by a thorax radiographic study. However, the result of a normal radiographic examination is not synonymous with the absence of possibly metastatic lesions $[1,7,25]$, as chest radiographs are only able to detect pulmonary nodules larger than $4-5 \mathrm{~mm}$ [1]. Abdominal ultrasound may also show changes in the structure and morphology of the abdominal organs [7, 26]. Another patient with primary nodules in the abdominal mammary gland had secondary nodules in the abdomen, characterized by splenic and hepatic nodules and development of several other intra-abdominal nodules. These lesions were presumed metastatic in the absence of histopathological sampling. It is estimated that $50 \%$ to $70 \%$ of cats with malignant mammary neoplasms without signs of metastasis at clinical evaluation will still develop metastatic lesions $[1,7,19,25]$. In addition, there are other imaging methods much more sensitive to detect small metastatic lesions as computed tomography [26-32], magnetic resonance imaging [26, 29], and scintigraphy $[1,25]$.

The presence of accessory lymph nodes in cats has been described in the literature, and they can present from 1 to 4 lymph nodes performing axillary and inguinal drainage of mammary glands $[33,34]$. In the ultrasound examination, 
TABle 3: Relative frequencies (\%) of the reproductive and ultrasound features (mammary glands, mammary ducts, and lymph nodes) in cats without (G1, $n=22)$ and with (G2, $n=10)$ mammary tumors.

\begin{tabular}{|c|c|c|}
\hline Features & G1 (\%) & G2 (\%) \\
\hline \multicolumn{3}{|l|}{ Reproductive } \\
\hline Neutered & 63.6 & 30.0 \\
\hline Progestogens & 31.2 & 100.0 \\
\hline Pregnancy & 22.7 & 50.0 \\
\hline \multicolumn{3}{|l|}{ Mammary glands } \\
\hline Homogeneous & 95.0 & 54.2 \\
\hline Heterogeneous & 5.0 & 45.8 \\
\hline Hypoechoic & 75.0 & 95.8 \\
\hline Isoechoic & 25.0 & 0 \\
\hline Anechoic & 0 & 4.2 \\
\hline \multicolumn{3}{|l|}{ Mammary ducts } \\
\hline Present & 10.0 & 31.3 \\
\hline Absent & 90.0 & 68.8 \\
\hline \multicolumn{3}{|l|}{ Mammary vascularization } \\
\hline Normal vascularization & 95.5 & 10 \\
\hline Hypervascularization & 4.5 & 90 \\
\hline \multicolumn{3}{|l|}{ Lymph nodes } \\
\hline Oval & 100.0 & 57.1 \\
\hline Rounded & 0 & 28.6 \\
\hline Lobed & 0 & 14.3 \\
\hline Homogeneous & 100.0 & 85.7 \\
\hline Heterogeneous & 0 & 14.3 \\
\hline Hypoechoic & 98.0 & 85.7 \\
\hline Hyperechoic & 0 & 14.3 \\
\hline Isoechoic & 2.0 & 0 \\
\hline Hyperechogenic central line & 67.0 & 7.5 \\
\hline Regular margin & 100.0 & 85.7 \\
\hline Irregular margin & 0 & 14.3 \\
\hline Normal vascularization & 100.0 & 85.7 \\
\hline Hypervascularization & 0 & 14.3 \\
\hline
\end{tabular}

changes in lymph node architecture may be suggestive of neoplastic involvement, especially when there is loss of central hyperechogenic hilus visibility and rounding [35-37]. These characteristics were present, respectively, in $92.5 \%$ and $28.57 \%$ of the lymph nodes evaluated in G2, but the conclusive diagnosis should be made through cytological and histopathological studies of these lymph nodes, and further research will be necessary to study this relationship.

\section{Conclusions}

Using longitudinal and transverse planes in the breasts and both lymph nodes are possible to evaluate the entire mammary chain, superficial inguinal lymph nodes, and axillary lymph nodes in the B-mode ultrasound examination. The ultrasound examination of the normal mammary chain is less than $2 \mathrm{~mm}$ thick and may increase during estrus, pregnancy, and lactation. The patterns of normal mammary gland images are usually hypoechoic and homogeneous echotexture, with defined and regular margins, and may have mammary ducts during estrus and diestrus when in the gestational or lactation phase. In abnormal mammary chains, the gland increases in volume width and may lose definition and regularity of the margins, with more frequent mammary ducts, and may be hypoechoic or anechoic, of homogeneous or heterogeneous texture. Lymph nodes in tumor-affected mammary chains may present changes in size, shape, echotexture, and echogenicity. In Doppler mode, caudal superficial epigastric artery and hilar lymphatic vascularization in normal mammary chains are identified, and in tumor-bearing cats, peripheral neovascularization or mixed patterns in a mammary tumor and lymph node tissue are identified.

\section{Data Availability}

The raw data used to support the findings of this study are available from the author upon request.

\section{Conflicts of Interest}

The authors declare that there are no conflicts of interest regarding the publication of this paper.

\section{Acknowledgments}

The authors would like to thank Dr. Marcelo Seixo de Brito e Silva (deceased) for all the help and support during the development of this research. Funds for publication costs were provided by FAPEG. The authors also acknowledge the financial support with a scholarship during the postgraduation course given by CAPES, process no. $88882.385856 /$ 2019-01.

\section{References}

[1] P. S. Castelo-Branco, G. Gutfilen-Schlesinger, P. Sena, G. Gutfilen-Schlesinger, S. A. L. Souza, and B. Gutfilen, "Detection of mammary adenocarcinoma metastases in a cat through ${ }^{99 \mathrm{~m}}$ Tc-thymine scintigraphy," Veterinaria México AO, vol. 7, no. 2, pp. 1-9, 2020.

[2] C. R. Daleck, P. H. Franceschini, A. C. Alessi, Á. E. Santana, and M. I. M. Martins, "Aspectos clínico e cirúrgicos do tumor mamário canino: clinical and surgical evolution," Ciência Rural, vol. 28, no. 1, pp. 95-100, 1998.

[3] M. Furian, C. F. C. S. Sandei, E. J. N. Rocha, and R. F. S. Lot, "Estudo retrospectivo dos tumores mamários em caninos e felinos atendidos no hospital veterinário da FAMED entre 2003 a 2007," Revista Científica Eletrônica de Medicina Veterinária, vol. 4, no. 8, pp. 20-24, 2007.

[4] C. S. Baptista, S. Santos, A. Laso et al., "Sequence variation and mRNA expression of the TWIST1 gene in cats with mammary hyperplasia and neoplasia," The Veterinary Journal, vol. 191, no. 2, pp. 203-207, 2012.

[5] A. A. Hayes and S. Mooney, "Feline mammary tumors," Veterinary Clinics of North America: Small Animal Practice, vol. 15, no. 3, pp. 513-520, 1985.

[6] J. Morris, "Mammary tumours in the cat: size matters, so early intervention saves lives," Journal of Feline Medicine and Surgery, vol. 15, no. 5, pp. 391-400, 2013.

[7] G. Petrucci, J. Henriques, H. Gregório et al., "Metastatic feline mammary cancer: prognostic factors, outcome and comparison of different treatment modalities-a retrospective multicentre study," Journal of Feline Medicine and Surgery, vol. 23, no. 6, pp. 549-556, 2020. 
[8] V. Zappulli, G. De Zan, B. Cardazzo, L. Bargelloni, and M. Castagnaro, "Feline mammary tumours in comparative oncology," Journal of Dairy Research, vol. 72, no. 1, pp. 98-106, 2005.

[9] F. Gemignani, P. D. Mayhew, M. A. Giuffrida et al., "Association of surgical approach with complication rate, progression-free survival time, and disease-specific survival time in cats with mammary adenocarcinoma: 107 cases (1991-2014)," Journal of the American Veterinary Medical Association, vol. 252, no. 11, pp. 1393-1402, 2018.

[10] H. T. Nyman, A. T. Kristensen, M. H. Lee, T. Martinussen, and F. J. Mcevoy, "Characterization of canine superficial tumors using gray-scale B mode, color flow mapping, and spectral doppler ultrasonography-a multivariate study," Veterinary Radiology Ultrasound, vol. 47, no. 2, pp. 192-198, 2006.

[11] R. Payan-Carreira and A. C. Martins-Bessa, "Ultrasonographic assessment of the feline mammary gland," Journal of Feline Medicine and Surgery, vol. 10, no. 5, pp. 466-471, 2008.

[12] F. V. Amorim, H. J. M. Souza, A. M. R. Ferreira, and A. B. M. Fonseca, "Clinical, cytological and histopathological evaluation of mammary masses in cats from Rio de Janeiro, Brazil," Journal of Feline Medicine and Surgery, vol. 8, no. 6, pp. 379-388, 2006.

[13] N. Masciadri and C. Ferranti, "Benign breast lesions: ultrasound," Journal of Ultrasound, vol. 14, no. 2, pp. 55-65, 2011.

[14] F. R. Reis, A. P. B. Barreira, V. Castro, J. L. C. Castro, S. M. C. Suzano, and A. A. Rocha, "Indícios sobre a correlação entre diferentes métodos diagnósticos em casos de tumor de mama em cadelas," Revista Eletrônica Novo Enfoque, vol. 9, no. 9, pp. 14-31, 2010.

[15] C. M. Sehgal, S. P. Weinstein, P. H. Arger, and E. F. Conant, "A review of breast ultrasound," Journal of Mammary Gland Biology and Neoplasia, vol. 11, no. 2, pp. 113-123, 2006.

[16] I. A. Silver, "Symposium on mammary neoplasia in the dog and cat-I the anatomy of the mammary gland of the dog and cat," Journal of Small Animal Practice, vol. 7, no. 11, pp. 689-696, 1966.

[17] B. Overley, F. S. Shofer, M. H. Goldschmidt, D. Sherer, and K. U. Sorenmo, "Association between ovarihysterectomy and feline mammary carcinoma," Journal of Veterinary Internal Medicine, vol. 19, no. 4, pp. 560-563, 2005.

[18] K. U. Sorenmo, R. Rasotto, V. Zappulli, and M. H. Goldschmidt, "Development, anatomy, histology, lymphatic drainage, clinical features, and cell differentiation markers of canine mammary gland neoplasms," Veterinary Pathology, vol. 48, no. 1, pp. 85-97, 2011.

[19] W. Misdorp, "Tumors of the mammary gland," in Tumors in Domestic Animals, pp. 575-606, Iowa State Press, Lowa City, IA, USA, 2002.

[20] W. Misdorp, R. W. Else, E. Hellmén, and T. P. Lipscomb, "Histological classification of mammary tumors of the dog and the cat," in World Health Organization International Histological Classification of Tumors of Domestic Animals, Armed Forces Institute of Pathology in Cooperation with the American Registry of Pathology and the World Health Organization Collaborating Center for Worldwide Reference on Comparative Oncology, Washington, DC, USA, 2nd edition, 1999.

[21] K. Weijer and A. A. M. Hart, "Prognostic factors in feline mammary carcinoma," JNCI: Journal of the National Cancer Institute, vol. 70, no. 4, pp. 709-716, 1983.

[22] C. L. Ackermann, T. F. P. da Silva, L. Daniel, M. da Silva, and M. D. Lopes, "Métodos contraceptivos em gatas domésticas- revisão de literatura," Ciência Animal, vol. 24, no. 2, pp. 41-54, 2014.

[23] M. Bocardo, D. M. M. Dabus, T. D. C. Tentrin, G. D. S. Lima, and M. H. Bariani, "Influência hormonal na carcinogênese mamária em cadelas," Revista Científica Eletrônica de Medicina Veterinária, vol. 6, no. 11, pp. 1-6, 2008.

[24] L. Howe, "Current perspectives on the optimal age to spay/ castrate dogs and cats," Veterinary Medicine: Research and Reports, vol. 6, pp. 171-180, 2015.

[25] P. S. M. Castelo-Branco, P. Sena, S. A. L. de Souza et al., "Diagnóstico precoce de metástase pulmonar: comparação entre a radiografia convencional e a cintilografia com timina-

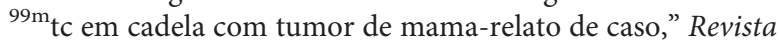
Brasileira de Medicina Veterinária, vol. 35, no. 3, pp. 267-271, 2013.

[26] J. S. Mattoon and J. N. Bryan, "The future of imaging in veterinary oncology: learning from human medicine," The Veterinary Journal, vol. 197, no. 3, pp. 541-552, 2013.

[27] S. Aarsvold, J. A. Reetz, J. K. Reichle et al., "Computed tomographic findings in 57 cats with primary pulmonary neoplasia," Veterinary Radiology \& Ultrasound, vol. 56, no. 3, pp. 272-277, 2015.

[28] L. J. Forrest, "Computed tomography imaging in oncology," Veterinary Clinics of North America: Small Animal Practice, vol. 46, no. 3, pp. 499-513, 2016.

[29] M. E. Menezes, S. K. Das, I. Minn et al., "Detecting tumor metastases: the road to therapy starts here," Molecular and Cellular Basis of Metastasis: Road to Therapy, vol. 132, pp. 1-44, 2016.

[30] C. C. Otoni, S. C. Rahal, L. C. Vulcano et al., "Survey radiography and computerized tomography imaging of the thorax in female dogs with mammary tumors," Acta Veterinaria Scandinavica, vol. 52, no. 1, pp. 1-10, 2010.

[31] M. N. Patsikas, P. L. Papadopoulou, A. Charitanti et al., "Computed tomography and radiographic indirect lymphography for visualization of mammary lymphatic vessels and the sentinel lymph node in normal cats," Veterinary Radiology \& Ultrasound, vol. 51, no. 3, pp. 299-304, 2010.

[32] A. C. B. D. C. F. Pinto, M. Iwasaki, C. M. D. Figueiredo, S. R. G. Cortopassi, and F. D. A. Sterman, "Tomografia computadorizada do tórax de cadelas portadoras de neoplasias malignas: II-avaliação dos campos pulmonares," Brazilian Journal of Veterinary Research and Animal Science, vol. 44, no. 3, pp. 174-182, 2007.

[33] World Association of Veterinary Anatomists and International Committee on Veterinary Anatomical Nomenclature, Nomina Anatomica Veterinaria, Adolf Holzhausen's Successors, Vienna, Austria, 6th edition, 2017.

[34] P. L. Papadopoulou, M. N. Patsikas, A. Charitanti et al., "The lymph drainage pattern of the mammary glands in the cat: a lymphographic and computerized tomography lymphographic study," Anatomia, Histologia, Embryologia, vol. 38, no. 4, pp. 292-299, 2009.

[35] X.-W. Cui, "New ultrasound techniques for lymph node evaluation," World Journal of Gastroenterology, vol. 19, no. 30, pp. 4850-4860, 2013.

[36] H. T. Nyman, A. T. Kristensen, A. Flagstad, and F. J. McEvoy, "A review of the sonographic assessment of tumor metastases in liver and superficial lymph nodes," Veterinary Radiology \& Ultrasound, vol. 45, no. 5, pp. 438-448, 2004.

[37] F. Stan, A. Gudea, A. Damian et al., "Ultrasonographic algorithm for the assessment of sentinel lymph nodes that drain the mammary carcinomas in female dogs," Animals, vol. 10, no. 12, p. 2366, 2020. 